\title{
Correction to: Integrating and Interpreting Findings from the Latest Treatment as Prevention Trials
}

\author{
Marie A. Brault ${ }^{1}$ - Donna Spiegelman ${ }^{2} \cdot$ Salim S. Abdool Karim ${ }^{3} \cdot$ Sten H. Vermund ${ }^{4}$
}

Published online: 30 June 2020

(C) Springer Science+Business Media, LLC, part of Springer Nature 2020

\section{Correction to: Current HIV/AIDS Reports (2020) 17:249-258 https://doi.org/10.1007/s11904-020-00492-4}

The original version of this review article unfortunately contained a mistake in the category section. The Section Editor was inadvertently captured as "E Geng" instead of "SH Vermund".

The correct category is presented below:

\section{Treatment as Prevention (SH Vermund, Section Editor)}

Publisher's Note Springer Nature remains neutral with regard to jurisdictional claims in published maps and institutional affiliations.

The online version of the original article can be found at https://doi.org/ 10.1007/s11904-020-00492-4

Marie A. Brault

marie.brault@yale.edu

Donna Spiegelman

donna.spiegelman@yale.edu

Salim S. Abdool Karim

Salim.AbdoolKarim@caprisa.org

Sten H. Vermund

sten.vermund@yale.edu
Department of Social and Behavioral Sciences, Yale School of Public Health, New Haven, CT, USA

2 Department of Biostatistics; Center for Methods in Implementation and Prevention Sciences, Yale School of Public Health, New Haven, CT, USA

3 Centre for the AIDS Programme of Research in South Africa (CAPRISA), Department of Epidemiology, Mailman School of Public Health, Columbia University, New York, NY, USA

4 Department of Epidemiology of Microbial Diseases, Yale School of Public Health, New Haven, CT, USA 